\title{
Impact of a Novel Plant-based Treatment Option in Improving Pulmonary Function Markers in Patients with Chronic Obstructive Pulmonary Disease and Asthma
}

\author{
Sachin A Shah ${ }^{1}$, Ji Hyun Jamie Lee ${ }^{1}$, Frank Son ${ }^{1}$, Gloria St John ${ }^{1,2}$ and Narinder Singh Parhar ${ }^{*}$ \\ ${ }^{1}$ Thomas J Long School of Pharmacy and Health Sciences, University of the Pacific, Stockton, CA, USA \\ ${ }^{2}$ Parhar Health Systems, Roseville, CA, USA \\ "Corresponding author: Narinder Singh Parhar, MD, Sutter Independent Physician, Parhar Health Systems, 584 N. Sunrise Avenue, \#100, Roseville, California 95661, \\ Brazil, Tel: (916) 773-2990; Fax: (916) 773-5154; E-mail: Parharmd@gmail.com
}

Received date: March 11, 2016; Accepted date: April 07, 2016; Publication date: April 11, 2016

Copyright: $\odot 2016$ Shah SA, et al. This is an open-access article distributed under the terms of the Creative Commons Attribution License, which permits unrestricted use, distribution, and reproduction in any medium, provided the original author and source are credited.

\begin{abstract}
Introduction: COPD and asthma contribute to high morbidity and mortality along with a significant social and economic burden. Patients often turn to Nutraceuticals as adjunct therapy for disease management. Jeeva ${ }^{\circledR}$ is a novel plant based therapeutic option that integrates several nutraceuticals known to have immune-modulatory, antiinflammatory and antioxidant properties. We sought to determine the magnitude of benefits of this novel integrative approach in patients having COPD \pm asthma.

Methods: A retrospective evaluation of patient records was performed for all COPD and/or asthma patients who had consented to initiate Jeeva ${ }^{\circledR}$. Demographic data, past medical history, and spirometry data (FEV1, FVC, FEV1/ FVC, FEV1\% predicted, FVC \% predicted, FEV1/FVC\% predicted) were collected. The primary endpoint was the maximum change in FEV1 and FVC pre-bronchodilator from baseline. A paired students' t-test was utilized to compare the maximum change post- Jeeva ${ }^{\circledR}$ from baseline. Intent-to-treat (ITT) analysis was performed using the last-observation carried forward methodology.
\end{abstract}

Results: A total of 24 patients were included for analyses. The average duration of Jeeva ${ }^{\circledR}$ consumption was $10.4 \pm 5.5$ months. There was a statistically significant change in FEV1 and FVC from baseline $[1.72 \pm 0.56 \mathrm{~L}$ to 1.98 $\pm 0.71 \mathrm{~L} ;(p<0.001)$ and $1.88 \pm 0.72 \mathrm{~L}$ to $2.03 \pm 0.70 \mathrm{~L}(p=0.004)$ respectively]. All other endpoints also improved significantly from baseline.

Conclusion: Jeeva ${ }^{\circledR}$ improved pre-bronchodilator FEV1 and FVC by $264 \mathrm{~mL}$ and $314 \mathrm{ml}$ from baseline. This is the first study suggesting significant improvements in objectively measured PFT markers after consumption of the plant-based nutraceutical Jeeva ${ }^{\circledR}$. Further studies looking at Jeeva ${ }^{\circledR}$ in prospective, controlled settings are warranted.

Keywords: COPD; Asthma; Nutraceuticals

\section{Introduction}

Chronic Obstructive Pulmonary Disease (COPD) and asthma are major causes of morbidity and mortality globally with COPD being the third leading cause of death [1]. COPD usually leads to persistent and progressive airflow limitations with enhanced chronic inflammatory responses and fibrosis in the airways that impacts activities of daily living and quality of life. According to the CDC, asthma accounts for one-quarter of all emergency room visits in the U.S. each year and over 3,000 deaths each year [2]. Although preventable to a certain degree and definitely manageable, COPD and asthma result in a significant social and economic burden [3].

The estimated total cost for the two conditions was approximately $\$ 68$ billion in 2008 [4]. Starting in 2015, the Centers for Medicare and Medicaid Services (CMS) plans to expand its Hospital Readmission Reduction Program (HRRP) to include COPD. This is driven by the fact that $23 \%$ of COPD hospitalizations are subsequently readmitted within 30 days post discharge [5].
Current pharmacologic options for the management of COPD and asthma typically include short acting and long acting beta2-agonists, anticholinergics, and inhaled glucocorticoids. However, none of the existing medications or regimens have been conclusively shown to modify the long-term decline in lung function [6].

Nutraceuticals often provide an alternative or are complementary for the disease management for several disease states such as diabetes (Cinnamon, Aloe vera), dyslipidemia (Red yeast rice), the common cold (Echinacea), depression (St. John's Wort) [7-11].

Several plant based therapeutic options such as ginseng extract, yiqibushenhuoxue decoction, Bufei granules, and Weijing decoction have been purported to have pulmonary function improving properties [12-15]. Jeeva ${ }^{\circledR}$ is a novel plant based therapeutic option that integrates several nutraceuticals known to have immune-modulatory, anti-inflammatory and antioxidant properties (Table 1) [16-32].

It integrates Arabinogalactan, Acai berry, concentrated Aloe polysaccharides, Bilberry, Gum Acacia, Star Anise, and Turmeric Root in varying doses and is available in a capsule form [16]. 
Citation: Shah SA, Lee HJJ, Son F, John G St, Parhar NS (2016) Impact of a Novel Plant-based Treatment Option in Improving Pulmonary Function Markers in Patients with Chronic Obstructive Pulmonary Disease and Asthma. Altern Integr Med 5: 215. doi: $10.4172 / 2327-5162.1000215$

Page 2 of 5

Many patients claim to have improved disease related quality of life, but no systematic evaluation has been performed with Jeeva ${ }^{\circledR}$. We completed the first retrospective assessment of patients having COPD and asthma treated with Jeeva ${ }^{\circledR}$ at a private physician's office.

\begin{tabular}{|l|c|c|c|}
\hline Ingredients & Antioxidant & Anti-inflammatory & Anti-microbial \\
\hline $\begin{array}{l}\text { Arabinogalactan [17,18] } \\
\text { Larix decidua }\end{array}$ & $\checkmark$ & & $\checkmark$ \\
\hline $\begin{array}{l}\text { Acai berry [19,20] } \\
\text { Euterpe oleracea }\end{array}$ & $\checkmark$ & $\checkmark$ & $\checkmark$ \\
\hline $\begin{array}{l}\text { Aloe Vera [21-23] } \\
\text { Aloe barbadensis }\end{array}$ & $\checkmark$ & $\checkmark$ & $\checkmark$ \\
\hline $\begin{array}{l}\text { Bilberry } \\
\text { Vaccinium mytillus }\end{array}$ & & $\checkmark$ & $\checkmark$ \\
\hline $\begin{array}{l}\text { Gum Acacia [27] } \\
\text { Acacia senegal }\end{array}$ & $\checkmark$ & $\checkmark$ & $\checkmark$ \\
\hline $\begin{array}{l}\text { Star Anise [28-30] } \\
\text { Illicium verum }\end{array}$ & $\checkmark$ & & $\checkmark$ \\
\hline $\begin{array}{l}\text { Turmeric Root [31,32] } \\
\text { Curcuma longa }\end{array}$ & & & $\checkmark$ \\
\hline
\end{tabular}

Table 1: Biological activity of ingredients in Jeeva ${ }^{\circledR}$.

\section{Methods}

We performed a retrospective evaluation of patient records from 2012 to 2014 at a private physician's office in Roseville, California. The primary practitioner specializes in internal medicine and holds board certification in the practice of alternative medicine. All patients voluntarily signed an informed consent document before initiation of Jeeva ${ }^{\circledR}$.

Patients were selected for analysis if having a diagnosis of COPD and/or asthma, and consumed Jeeva ${ }^{\circledR}$ (1-3 capsules daily based on clinical judgement) for at least 90 days in addition to standard of care.

Patients were only included if having baseline and at least 1 follow up visit with spirometry data (FEV1 and FVC measurements).

Forced expiratory volume in 1 second (FEV1), defines the volume of air that can be forced out in one second after taking a deep breath and forced vital capacity (FVC) measures the volume of air forcibly exhaled from the point of maximal inspiration both of which are accepted objective markers of pulmonary function. Those under 18 years of age were excluded. Patients were not excluded based on any co-morbidity.

A comprehensive chart review was conducted to collect demographic data, past medical history, and spirometry data. Medication history was collected but not tracked serially due to the limited availability of data.

Pulmonary function test parameters (FEV1, FVC, FEV1/FVC, FEV1\% predicted, FVC\% predicted, FEV1/FVC $\%$ predicted) were extracted at baseline and for each subsequent visit with available spirometry data.

The primary endpoint was the maximum change in FEV1 and FVC pre-bronchodilator from baseline. Secondary endpoints included the maximum change from baseline in FEV1 post-bronchodilator, FEV1\% predicted pre-bronchodilator, FEV1\% predicted post-bronchodilator,
FVC post-bronchodilator, FVC\% predicted pre-bronchodilator, FVC\% predicted post-bronchodilator, FEV1/FVC pre-bronchodilator, FEV1/FVC post-bronchodilator, FEV1/FVC\% predicted prebronchodilator, and $\mathrm{FEV} 1 / \mathrm{FVC} \%$ predicted post-bronchodilator.

A paired students' t-test was utilized to compare the baseline to the max change post- Jeeva ${ }^{\circledR}$ for all endpoints with a $\mathrm{p}<0.05$ considered significant. For patients with missing data, an intent-to-treat (ITT) analysis was performed using the last-observation carried forward methodology.

Since some patients had exaggerated effects, changes in FEV1 and FVC $>1 \mathrm{~L}$ from baseline and $>0.20$ with FEV1/FVC from baseline were considered as outliers and excluded.

\section{Results}

A total of 24 patients were included for analyses. Sixteen patients were male $(66 \%)$ with eight $(33 \%)$ were Female. The average age and weight were $72 \pm 12$ years and $84 \pm 15 \mathrm{~kg}$ respectively. All had COPD with 13 (54\%) having concomitant asthma. Seventeen (71\%) were former smokers and one (4\%) was a current smoker.

Fourteen patients (58\%) had hypertension, six (25\%) had diabetes and six $(25 \%)$ had coronary artery disease. Relevant comorbid past medical history included allergic rhinitis (63\%), anxiety (29\%), and chronic sinusitis (13\%). Twelve patients were on short acting beta-2 agonists (50\%), eleven on a long acting beta- 2 agonist and corticosteroid combination (46\%), six on anticholinergics (25\%), two on inhaled corticosteroids (8\%), and one on a leukotriene modifier (4\%). Average duration of Jeeva ${ }^{\circledR}$ consumption was $10.4 \pm 5.5$ months.

FEV1 pre-bronchodilator improved significantly from baseline (1.72 $\pm 0.56 \mathrm{~L}$ to $1.98 \pm 0.71 \mathrm{~L} ; \mathrm{p}<0.001$ ) (Figure $1 \mathrm{a}$ ). FEV1 postbronchodilator improved significantly from $1.88 \pm 0.72 \mathrm{~L}$ to $2.03 \pm 0.70$ 
Citation: Shah SA, Lee HJJ, Son F, John G St, Parhar NS (2016) Impact of a Novel Plant-based Treatment Option in Improving Pulmonary Function Markers in Patients with Chronic Obstructive Pulmonary Disease and Asthma. Altern Integr Med 5: 215. doi: $10.4172 / 2327-5162.1000215$

Page 3 of 5

$\mathrm{L}(\mathrm{p}=0.004)$. FEV1 \% predicted pre- and post-bronchodilator also improved significantly (Table 1 ).

FVC pre-bronchodilator improved significantly from baseline (2.49 $\pm 0.66 \mathrm{~L}$ to $2.81 \pm 0.73 \mathrm{~L} ; \mathrm{p}<0.001$ ) (Figure $1 \mathrm{~b}$ ). FVC postbronchodilator improved significantly from $2.73 \pm 0.82 \mathrm{~L}$ to $2.83 \pm 0.81$ $\mathrm{L}(\mathrm{p}=0.006)$. FVC\% predicted pre and post-bronchodilator also improved significantly (Table 1).

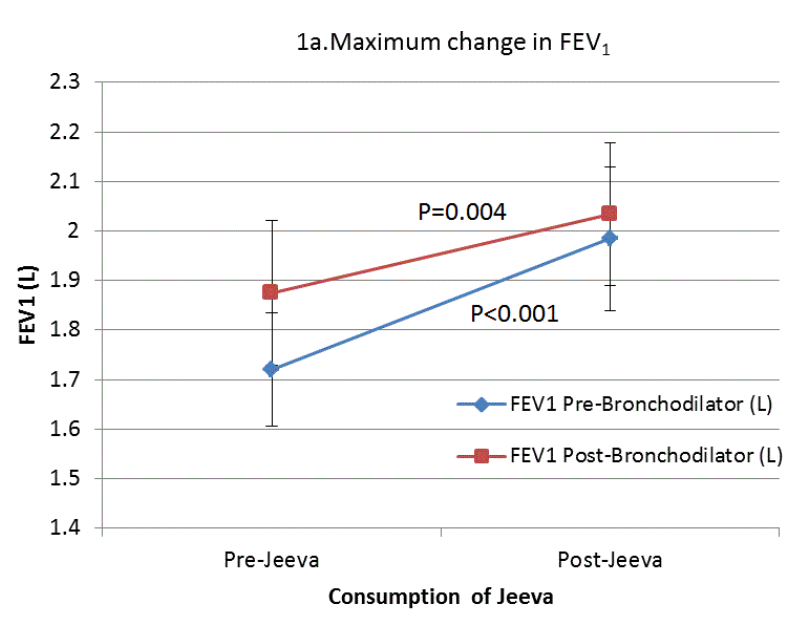

1b.Maximum change in FVC

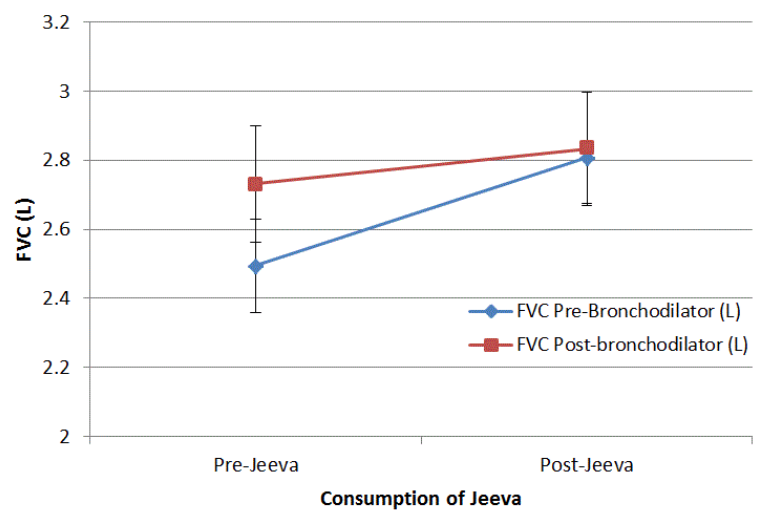

Figure 1: Maximum change in FEV1 and FVC.

FEV1/FVC pre-bronchodilator improved significantly from baseline $(0.69 \pm 0.16$ to $0.77 \pm 0.14 ; \mathrm{p}<0.001)$. FEV1/FVC post-bronchodilator improved significantly from $0.68 \pm 0.14$ to $0.74 \pm 0.12(\mathrm{p}<0.001)$. FEV1/FVC\% predicted pre-bronchodilator improved significantly from baseline $(94.3 \pm 21.5$ to $103.4 \pm 20.9 ; \mathrm{p}<0.001)$. FEV1/FVC\% predicted post-bronchodilator improved significantly from $93.2 \pm 19.4$ to $100.8 \pm 16.1(\mathrm{p}=0.001)$.

\section{Discussion}

In our assessment of patients consuming Jeeva ${ }^{\circledR}$ for over 10 months, FEV1 and FVC pre-bronchodilator increased by $264 \mathrm{~mL}$ and $314 \mathrm{ml}$ from baseline respectively. In a randomized, double-blind study by Murali et al., a proprietary product DCBT1234-Lung KR was compared to a salbutamol/theophylline/bromhexine combination and a lactose placebo [33]. After 6 months $(n=39)$ FEV1 changed significantly from $1.32 \pm 0.61 \mathrm{~L}$ to $1.50 \pm 0.72 \mathrm{~L}$ post DCBT1234-Lung KR. The comparator arms showed non-significant changes. In another study ginseng extract significantly increased FEV1 and FVC by $27 \%$ and $32.5 \%$ from baseline [12]. The impact of salmeterol, fluticasone, and salmeterol/fluticasone combination on pulmonary function parameters was compared in a randomized controlled trial [34]. After 12 months of treatment, the changes in FEV1 pre-bronchodilator from baseline were $78 \mathrm{ml}, 41 \mathrm{ml}$, and $88 \mathrm{ml}$ in the three groups respectively. Similarly, the mean improvements in FVC were $139 \mathrm{~mL}, 57 \mathrm{~mL}$, and 57 $\mathrm{mL}$ after salmeterol, fluticasone, and salmeterol/fluticasone combination, respectively [34].

The respiratory system undergoes various physiological, immunological, and anatomical changes with age [35]. The estimated rate of decline in FEV1 is $25-30 \mathrm{~mL} / \mathrm{yr}$ starting at age of $35-40$ years and can double to $60 \mathrm{~mL} / \mathrm{yr}$ after the age of 70 years [35]. FVC generally declines at approximately $22 \mathrm{~mL} / \mathrm{yr}$ in healthy subjects (20 to 60 years) [36].

Chronic inflammation in the lungs can lead to narrowing of airways, destruction of parenchymal tissues, and other structural damages leading to a further decline in pulmonary function [36]. Jeeva ${ }^{\circledR}$ contains ingredients with anti-inflammatory, antioxidant, and immunomodulatory properties (Table 1 ) potentially explaining the mechanism behind the benefits seen in PFT markers. Based on some of the known literature on the ingredients, Jeeva ${ }^{\circledR}$ may be beneficial in long-term disease prognosis and reversibility of COPD.

There is a direct relationship between the severity of COPD and the cost of care justifying an accurate cost-benefit analysis of the available therapeutic options [37]. It is believed that the cost of estimated medical expenditure for COPD (\$2507/year per patient) often underrepresent the true costs [38]. Factoring in sociodemographic characteristics (age, race, education level, etc.) and indirect costs (care provided by family member), the true adjusted cost of COPD is anticipated to be much higher at $\$ 4932 /$ year per patient [38].

In our analyses, Jeeva ${ }^{\circledR}$ posed benefits of similar magnitude (P FT parameters) and of clinical importance warranting further investigations. Whether Jeeva ${ }^{\circledR}$ used as monotherapy, or complementary to the current pharmacotherapeutic standard-of-care for COPD/asthma needs future evaluation.

Our analysis has several limitations worth noting. We could not evaluate changes in medications due to limited data. It is possible that the large magnitude of benefit seen in our results is compounded by concurrent changes in medications. A systematic assessment of patient symptoms and adverse effects was not extracted. Further, disease related hospital admissions were not assessed. Future studies should assess hospital readmission along with a standardized assessment of quality of life.

A lack of a control arm and a small sample size pose inherent limitations in data extrapolation and wide applicability. While Jeeva ${ }^{\circledR}$ is manufactured by an FDA approved manufacturer, the potency of herbal raw ingredients can vary based on the location and season of the harvest making it difficult to ascertain standardization in Jeeva ${ }^{\circledR}$ capsules [39]. Since the active moieties of the different herbal ingredients in Jeeva ${ }^{\circledR}$ need further discovery, an understanding of the pharmacokinetic profile remains unknown (Table 2). 
Citation: Shah SA, Lee HJJ, Son F, John G St, Parhar NS (2016) Impact of a Novel Plant-based Treatment Option in Improving Pulmonary Function Markers in Patients with Chronic Obstructive Pulmonary Disease and Asthma. Altern Integr Med 5: 215. doi: $10.4172 / 2327-5162.1000215$

Page 4 of 5

\begin{tabular}{|c|c|c|c|}
\hline PFT parameters & Baseline & Max change & $p$-value \\
\hline FEV1 (Liters) & $1.72 \pm 0.56$ & $1.98 \pm 0.71$ & $p<0.001$ \\
\hline $\begin{array}{l}\text { FEV1 (Liters) } \\
\text { [post-bronchodilator] }\end{array}$ & $1.88 \pm 0.72$ & $2.03 \pm 0.70$ & $p=0.004$ \\
\hline FEV1\% predicted & $60.1 \pm 14.0$ & $68.1 \pm 20.3$ & $p=0.002$ \\
\hline $\begin{array}{l}\text { FEV1\% predicted } \\
\text { [post-bronchodilator] }\end{array}$ & $66.67 \pm 27.7$ & $72.1 \pm 26.1$ & $p=0.004$ \\
\hline FVC (Liters) & $2.49 \pm 0.66$ & $2.81 \pm 0.73$ & $p<0.001$ \\
\hline $\begin{array}{l}\text { FVC (Liters) } \\
\text { [post-bronchodilator] }\end{array}$ & $2.73 \pm 0.82$ & $2.83 \pm 0.81$ & $p=0.006$ \\
\hline FVC\% predicted & $65.1 \pm 14.1$ & $72.2 \pm 13.9$ & $p=0.004$ \\
\hline $\begin{array}{l}\text { FVC\% predicted } \\
\text { [post-bronchodilator] }\end{array}$ & $65.1 \pm 19.1$ & $69.6 \pm 19.2$ & $p=0.003$ \\
\hline FEV1/FVC & $0.69 \pm 0.16$ & $0.77 \pm 0.14$ & $P<0.001$ \\
\hline $\begin{array}{l}\text { FEV1/FVC } \\
\text { [post-bronchodilator] }\end{array}$ & $0.68 \pm 0.14$ & $0.74 \pm 0.12$ & $P<0.001$ \\
\hline FEV1/FVC\% predicted & $94.3 \pm 21.5$ & $103.4 \pm 20.9$ & $p<0.001$ \\
\hline $\begin{array}{l}\text { FEV1/FVC\% predicted } \\
\text { [post-bronchodilator] }\end{array}$ & $93.2 \pm 19.4$ & $100.8 \pm 16.1$ & $p=0.001$ \\
\hline
\end{tabular}

Table 2: Impact of Jeeva ${ }^{\circledR}$ on PFT parameters.

\section{Conclusion}

Jeeva ${ }^{\circledR}$ improved pre-bronchodilator FEV1 and FVC by $264 \mathrm{~mL}$ and $314 \mathrm{ml}$ from baseline. This is the first study suggesting significant improvements in objectively measured PFT markers after consumption of the plant-based nutraceutical Jeeva ${ }^{\circledR}$. Further studies looking at $\mathrm{Jeeva}^{\circledR}$ in prospective, controlled settings are warranted.

\section{References}

1. World Health Report (2012) Geneva: World Health Organization.

2. Bousquet J, Bousquet PJ, Godard P, Daures JP (2005) The public health implications of asthma. Bull World Health Organ 83: 548-554.

3. The Global Burden of Disease (2004) World Health Organization.

4. National Heart, Lung, and Blood Institute (2010) Morbidity and mortality chartbook on cardiovascular, lung and blood disease. Bethesda, Maryland: US Department of Health and Human Services, Public Health Service, National Institutes of Health.

5. Jencks SF, Williams MV, Coleman EA (2009) Rehospitalizations among patients in the Medicare fee-for-service program. N Engl J Med 360: 1418-1428.

6. Anthonisen NR, Connett JE, Kiley JP, Altose MD, Bailey WC, et al. (1994) Effects of smoking intervention and the use of an inhaled anticholinergic bronchodilator on the rate of decline of FEV1. The Lung Health Study. JAMA 272: 1497-505.

7. Allen RW, Schwartzman E, Baker WL, Coleman CI, Phung OJ (2013) Cinnamon use in type 2 diabetes: an updated systematic review and meta-analysis. Ann Fam Med 11: 452-459.
8. Ngo MQ, Nguyen NN, Shah SA (2010) Oral aloe vera for treatment of diabetes mellitus and dyslipidemia. Am J Health Syst Pharm 67: 1804, 1806, 1808.

9. Li Y, Jiang L, Jia Z, Xin W, Yang S, et al. (2014) A meta-analysis of red yeast rice: an effective and relatively safe alternative approach for dyslipidemia. PLoS One 9: e98611.

10. Shah SA, Sander S, White CM, Rinaldi M, Coleman CI (2007) Evaluation of echinacea for the prevention and treatment of the common cold: a meta-analysis. Lancet Infect Dis 7: 473-480.

11. Bukhari IA, Dar A (2013) Behavioral profile of Hypericum perforatum (St. John's Wort) extract. A comparison with standard antidepressants in animal models of depression. Eur Rev Med Pharmacol Sci 17: 1082-1089.

12. Gross D, Shenkman Z, Bleiberg B, Dayan M, Gittelson M, et al. (2002) Ginseng improves pulmonary functions and exercise capacity in patients with COPD. Monaldi Arch Chest Dis 57: 242-246.

13. Liu J, Gao F, Li Z (2014) Effect of yiqibushenhuoxue decoction on chronic obstructive pulmonary disease measured by St. George's respiratory disease questionnaire scores and forced expiratory volume. J Tradit Chin Med 34: 445-449.

14. Guo S, Sun Z, Liu E, Feng J, Fu M, et al. (2014) Effect of bufei granule on stable chronic obstructive pulmonary disease: a randomized, double blinded, placebo-controlled, and multicenter clinical study. J Tradit Chin Med 34: 437-444.

15. Liu S, Shergis J, Chen X, Yu X, Guo X, et al. (2014) Chinese herbal medicine (weijing decoction) combined with pharmacotherapy for the treatment of acute exacerbations of chronic obstructive pulmonary disease. Evid Based Complement Alternat Med Epub 257012.

16. http://integrativepulmonarycarecenter.com/

17. Kelly GS (1999) Larch arabinogalactan: clinical relevance of a novel immune-enhancing polysaccharide. Altern Med Rev 4: 96-103. 
Citation: Shah SA, Lee HJJ, Son F, John G St, Parhar NS (2016) Impact of a Novel Plant-based Treatment Option in Improving Pulmonary Function Markers in Patients with Chronic Obstructive Pulmonary Disease and Asthma. Altern Integr Med 5: 215. doi: $10.4172 / 2327-5162.1000215$

Page 5 of 5

18. Chatterjee UR, Ray S, Micard V, Ghosh D, Ghosh K, et al. (2014) Interaction with bovine serum albumin of an anti-oxidative pectic arabinogalactan from Andrographis paniculata. Carbohydr Polym 101: 342-348.

19. Domej W, Oettl K, Renner W (2014) Oxidative stress and free radicals in COPD--implications and relevance for treatment. Int J Chron Obstruct Pulmon Dis 9: 1207-1224.

20. Skyberg JA, Rollins MF, Holderness JS, Marlenee NL, Schepetkin AI, et al. (2012) Nasal Acai Polysaccharides Potentiate Innate Immunity to Protect against Pulmonary Francisella tularensis and Burkholderia pseudomallei Infections. PLoS Pathogens 8: e1002587.

21. Manvitha K, Bidya B (2014) Aloe vera: a wonder plant its history, cultivation and medicinal uses. J Pharmacognosy and Phytochemistry 2: $85-88$

22. Zhong JS, Huang YY, Zhang TH, Liu YP, Ding WJ, et al. (2015) Natural phosphodiesterase-4 inhibitors from the leaf skin of Aloe barbadensis Miller. Fitoterapia 100: 68-74.

23. Habeeb F, Shakir E, Bradbury F, Cameron P, Taravati MR, et al. (2007) Screening methods used to determine the anti-microbial properties of Aloe vera inner gel. Methods 42: 315-320.

24. Hohtola A (2010) Bioactive compounds from northern plants. Adv Exp Med Biol 698: 99-109.

25. Burdulis D, Sarkinas A, Jasutiene I (2009) Comparative study of anthocyanin composition, antimicrobial and antioxidant activity in bilberry (Vaccinium myrtillus L.) and blueberry (Vaccinium corymbosum L.) fruits. Acta Poloniae Pharmaceutica 66: 399-408.

26. Braga PC, Antonacci R, Wang YY, Lattuada N, Sasso DM, et al. (2013) Comparative antioxidant activity of cultivated and wild Vaccinium species investigated by EPR, human neutrophil burst and COMET assay. European Review of Medical and Pharmacological Sciences 17: 1987-1999.

27. Ali BH, Ziada A, Blunden G (2009) Biological effects of gum arabic: a review of some recent research. Food Chem Toxicol 47: 1-8.
28. Benmalek Y, Yahia OA, Belkebir A, Fardeau ML (2013) Anti-microbial and anti-oxidant activities of Illicium verum, Crataegus oxyacantha ssp monogyna and Allium cepa red and white varieties. Bioengineered 4: 244-248.

29. De M, De AK, Sen P, Banerjee AB (2002) Antimicrobial properties of star anise (Illicium verum Hook f). Phytother Res 16: 94-95.

30. Kang P, Kim KY, Lee HS, Min SS, Seol GH, et al. (2013) Antiinflammatory effects of anethole in lipopolysaccharide-induced acute lung injury in mice. Life Sci 93: 955-961.

31. Shishodia S, Sethi G, Aggarwal BB (2005) Curcumin: getting back to the roots. Ann N Y Acad Sci 1056: 206-217.

32. Bengmark S, Mesa MD, Gil A (2009) Plant-derived health: the effects of turmeric and curcuminoids. Nutr Hosp 24: 273-281.

33. Murali PM, Rajasekaran S, Paramesh P, Krishnarahashekar OR, Vasudevan S, et al. (2006) Plant based formulation in the management of chronic obstructive pulmonary disease: A randomized double-blind study. Respiratory Med 100: 39-45.

34. Calverley P, Pauwels R, Vestbo J, Jones P, Pride N, et al. (2003) Combined salmeterol and fluticasone in the treatment of chronic obstructive pulmonary disease: a randomised controlled trial. Lancet 361: 449-456.

35. Sharma G, Goodwin J (2006) Effect of aging on respiratory system physiology and immunology. Clin Interv Aging 1: 253-260.

36. Swanney MP, Stanton JD, O’Reilly-Nugent A (2014) Natural decline in FEV1 and FVC: Self versus reference equations. ERJ 42: 1787.

37. Jansson SA, Andersson F, Borg S, Ericsson A, Jönsson E, et al. (2002) Costs of COPD in Sweden according to disease severity. Chest 122: 1994-2002.

38. Miller JD, Foster T, Boulanger L, Chace M, Russell MW, et al. (2005) Direct costs of COPD in the U.S.: an analysis of Medical Expenditure Panel Survey (MEPS) data. COPD 2: 311-318.

39. Fong $\mathrm{HH}$ (2002) Integration of herbal medicine into modern medical practices: issues and prospects. Integr Cancer Ther 1: 287-293. 